\title{
3D analysis of anatomical reactions in conifers after mechanical wounding: first qualitative insights from $\mathrm{X}$-ray computed tomography
}

\author{
M. Stoffel • M. Klinkmüller
}

Received: 20 April 2013/Revised: 19 June 2013/Accepted: 26 June 2013/Published online: 4 July 2013

(c) Springer-Verlag Berlin Heidelberg 2013

\begin{abstract}
The ability of trees to recover from damage beyond the last-formed periderm as well as the drivers and nature of associated wound reactions have been studied for more than two centuries using macroscopic (desiccation, aeration or discoloration of wood) and microscopic approaches (anatomical and chemical reactions). However, no studies currently exist which address large-scale macroscopic and microscopic reactions surrounding wounds in the tangential, axial, and radial directions over continuous segments of tree stems. This note explores the potential of 3D X-ray computed tomography in assessing effects of wounding under natural conditions in European conifers (Abies alba, Larix decidua, Picea abies). We present results from a pilot study and qualitatively evaluate the potential of the approach used in assessing and illustrating the formation and spread of de-differentiated xylem parenchyma cells, xylem decay compartmentalization, resin ducts, and stabilizing compression wood cells.
\end{abstract}

Keywords Computed tomography - 3D image analysis . Wound - Compression wood - Tangential row of traumatic resin ducts · Compartmentalization

Communicated by T. Fourcaud.

M. Stoffel ( $\square)$

Institute of Geological Sciences, University of Bern,

Baltzerstrasse 1+3, 3012 Bern, Switzerland

e-mail: markus.stoffel@dendrolab.ch

M. Stoffel · M. Klinkmüller

Institute for Environmental Sciences, University of Geneva,

1227 Carouge-Geneva, Switzerland

\section{Introduction}

The ability of trees to recover from damage beyond the last-formed periderm as well as the drivers and nature of associated wound reactions has been studied for more than two centuries (Hartig 1844; Bannan 1936; Delvaux et al. 2010). Traits have been described as protecting stems from the negative effects of damage, assisting them in overgrowing wounds and/or constraining pathogens and decay-producing organisms from spreading into adjacent tissues (Romero et al. 2009). Using a macroscopic approach, Shigo (1984) extensively analyzed the formation of protective and defensive tissues as a reaction to wounding [CODIT; also see Smith (2006) for a recent overview]. The main focus of macroscopic wound analysis has been either on desiccation and aeration of exposed tissues or on the discoloration of affected wood (Rademacher et al. 1984; Shortle et al. 2010). More recent work investigated the formation and properties of physical and chemical boundaries serving to wall off compromised tissues (Stobbe et al. 2002; Eyles et al. 2003). Trees have been demonstrated to respond immediately to wounding (Rier and Shigo 1972; Nagy et al. 2000; Cruickshank et al. 2006; Rajput et al. 2009) with the nature and type of reactions depending on the intensity of the mechanical impact and the size of the wound (Bollschweiler et al. 2008; Stoffel and Hitz 2008).

Past microscopic investigations of stem reactions to wounding focused on the production of resin and the formation of tangential rows of traumatic resin ducts (TRD). Most previous work was entirely experimental and studied damage inflicted artificially to small trees or seedlings (Ruel et al. 1998; Lev-Yadun 2002; Romero et al. 2009). The formation and extent of TRD has been 
studied for juvenile and adolescent European conifers (Abies alba, Larix decidua, Picea abies) using crosssections from various heights within, above and below wounds (Stoffel and Hitz 2008; Bollschweiler et al. 2008; Schneuwly et al. 2009a, b). These studies yielded valuable semi-point data, but no continuous threedimensional (3D) information on wound reactions.

Previous work addressing 3D analysis of living trees primarily focused on the identification of decay (e.g., cavities) or the role and spread of compartmentalization as a means to prevent decay (Brazee et al. 2010). Several approaches have been tested successfully in the past including stress wave timing (Lawday and Hodges 2000), ultrasonic tomography (Socco et al. 2004), magnetic resonance imaging (Müller et al. 2001), or electrical resistance and resistivity (Ostrofsky and Shortle 1989; Larsson et al. 2004). In their magnetic resonance imaging (MRI) analysis of Fagus sylvatica, Oven et al. (2008) were the first to focus on a continuous, 3D image of a wound rather than on decay, but their study focused on a single small injury inflicted to a tree branch. More recently, Seifert et al. (2010) investigated the long-term effects of pruning on wild cherry using CT. Nevertheless, no studies actually exist which address large-scale reactions around wounds (i.e. tangential, axial and radial directions) over continuous $(<15 \mathrm{~cm})$ segments of juvenile or adult $(\mathrm{DBH}>20 \mathrm{~cm})$ tree stems.

X-ray computed tomography (XRCT) was first developed in medicine (Oldendorf 1961; Cormack 1963) as it provides an accurate spatial distribution of the inner structure of objects (Duliu 1999). The potential of XRCT was rapidly recognized by non-medical sciences including dendrology (Lindgren et al. 1992; Wilkes et al. 2009) to determine the spatial distribution of internal structures and to facilitate pre-cutting decisions using artificial neural networks or maximum likelihood classifier (Sarigul et al. 2003; Wei et al. 2009). In dendrochronology, CT has been used primarily to measure the tree-ring widths in fragile, archeological objects (Bill et al. 2012).

This contribution therefore explores and illustrates possibilities and limitations of a 3D X-ray computed tomography (XRCT) assessment of wounds in European conifers (A. alba, L. decidua, and P. abies). Samples are shown with mechanical damage inflicted by falling rocks under natural conditions and wounds penetrating beyond the last-formed periderm. We present highly resolved 3D images, obtained with XRCT, and evaluate their potential in assessing and illustrating the formation and spread of (1) de-differentiated xylem parenchyma cells (i.e. callus tissue), (2) xylem decay compartmentalization, (3) resin and TRD, and (4) stabilizing compression wood cells.

\section{Materials and methods}

X-ray computed tomography

Three-dimensional data of wound reactions were gathered from large cross-sections (DBH $>20 \mathrm{~cm}$; stem segments $>15 \mathrm{~cm}$ ) of European conifers (A. alba, L. decidua and $P$. abies) using XRCT. XRCT is based on the attenuation of the X-ray beam by the object, thereby providing a set of absorption projections in 2D that can be reconstructed to obtain 3D structures (Duliu 1999). Depending on the energy, the density and effective atomic number of the material, XRCT yields qualitative data on local density within the wood. A total of 26 samples were scanned with a resolution of $1.25 \mathrm{~mm}$ using a Siemens Emotion 6 XRCT operated at $130 \mathrm{kV}$ and $200 \mathrm{~mA}$ beam current, resulting in projections with a size of $512 \times 512$ pixels. In this contribution, we illustrate one characteristic example of damage in common, juvenile to adult (36-53 years) L. decidua, P. abies, and A. alba.

\section{Qualitative image analysis}

Raw XRCT output data were stored as DICOM files (digital imaging and communication in medicine) and processed with Osirix (www.osirix-viewer.com; Rosset et al. 2004) using 256 gray values-expressed in Hounsfield Units (HU) - to identify macroscopic and microscopic features with a resolution of up to $\sim 0.3 \mathrm{~mm}$. Based on the Lambert-Beer law we then obtain maps of attenuation coefficients (Duliu 1999). A HU of $-1,096$ refers to air, the maximum density obtained for wood structures are 827 (resin or dense wood, e.g., reaction wood structures). Finer structures cannot be resolved with medical XRCT.

Further visualization was performed using the $3 \mathrm{D}$ volume rendering function in Osirix. Brightness and contrast values were adjusted for each sample to display zones with anomalous density. Highest densities are shown in white and bright yellow (corresponding to $700-800 \mathrm{HU}$ ), lower densities are displayed in red and have values of -200 to $300 \mathrm{HU}$, black structures are not visible.

\section{Results and discussion}

Four representative cross-sections are illustrated here from L. decidua, P. abies and A. alba. Samples exhibit considerable damage resulting from rock impacts and were airdried for several months prior to analyses so as to minimize residual humidity. Prior to XRCT analysis, we dated and documented growth anomalies with dendrogeomorphic techniques (Stoffel and Bollschweiler 2008; Stoffel et al. 2010). This macroscopic assessment yielded data on callus 

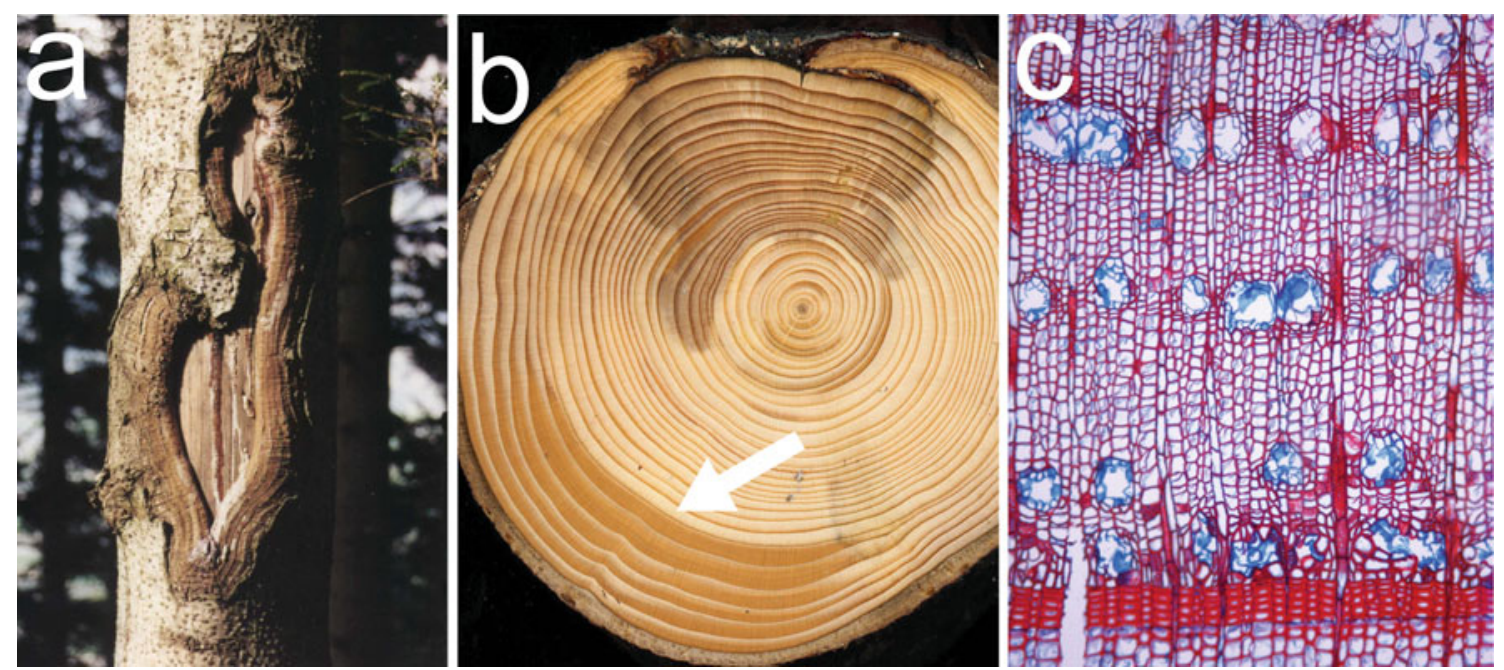

Fig. 1 Trees wounded by rockfall under natural conditions: a partly overgrown impact scar in A. alba Mill., b cross-section of $P$. abies (L.) Karst. with characteristic macroscopic wound effects including callus pad formation, compartmentalization and discoloration below

tissue formation, tangential rows of TRD, and reaction wood (i.e. compression wood) in 2D. Characteristic examples of wound and other growth reactions at the macroscopic level are presented in Fig. 1.

The main focus using XRCT was on the identification of callus tissue, TRD, reaction wood as well as possibly further growth anomalies and defense structures following wounding in 3D. Through the use of a medical XRCT, it is expected that the density of wound reactions and defense structures would be significant enough to allow for a distinction of different growth anomalies in the radial, tangential and axial dimension. This pilot study did not, in contrast, aim at resolving finer structures (such as individual growth rings in trees).

Figure 2 shows different XRCT images of a $L$. decidua cross-section with an almost entirely overgrown scar, which was inflicted to the tree 15 years before it was sampled for analysis. Tree rings, as seen in the grayscale raw XRCT data (Fig. 2, inset), are very distinct for a few years after wounding but poorly resolved in the innermost portion of the stem and for the outermost series of rings. These differences are partly due to ring width and clearly show the limitations of XRCT for microscopic analyses. Following wounding, the sampled $L$. decidua tree allocates its reserves to ring formation and wound closure (Fig. 2b), resulting in the formation of large, clearly visible rings. Before and after this temporal increase in ring width, the $L$. decidua tree illustrated in Fig. 2 produced increment rings which were too small to be resolved clearly in the raw XRCT image. In addition, wood decay in the rings formed prior to wounding also prevents a better visibility of growth rings in this segment of the cross-section. the wound as well as the formation of compression wood (arrow), c Microscopic wound features in L. decidua Mill. including tangentially aligned resin ducts

Detailed views of rings formed after wounding are provided in Fig. 2a, b. Zones illustrated in white and gray in the 3D XRCT image do not show any density anomalies. Highest densities are given in white and bright yellow, lower densities are displayed in red. The clear red and pink structures in the inner part of the cross-section are branches, and not of interest for the purpose of this study. Darker surfaces show rings with above-average densities. Macroscopic verification on the cross-section shows that these red and ruby surfaces represent areas of compression wood (lower part of Fig. 2a) or chaotic callus tissue (i.e. surfaces overgrowing the wound in Fig. 2a, a detailed view is provided in the micro-section of Fig. 2c).

Compression wood serves the stability of a tree and is characterized by much thicker walls and smaller lumina as compared to normal tracheids. The formation of compression wood following rockfall impact under natural condition proves to be exceptional and spatially limited in the present case; this feature is largely restricted to a small portion of the tree's circumference and to a few years after wounding. This observation in fact confirms findings from earlier 2D studies stating that $L$. decidua does not tend to be tilted by short, but intense impacts of rocks (Stoffel et al. 2005; Schneuwly and Stoffel 2008; Schneuwly et al. 2009a).

The denser wood structures overgrowing the wound from its edges represent chaotic callus tissue and show that the presence of denser wood structures is mostly limited to the latewood portion of the ring in the present case. We therefore speculated that the sampled $L$. decidua tree preferentially invested in wood production during earlywood to expedite wound closure and that stability of the 


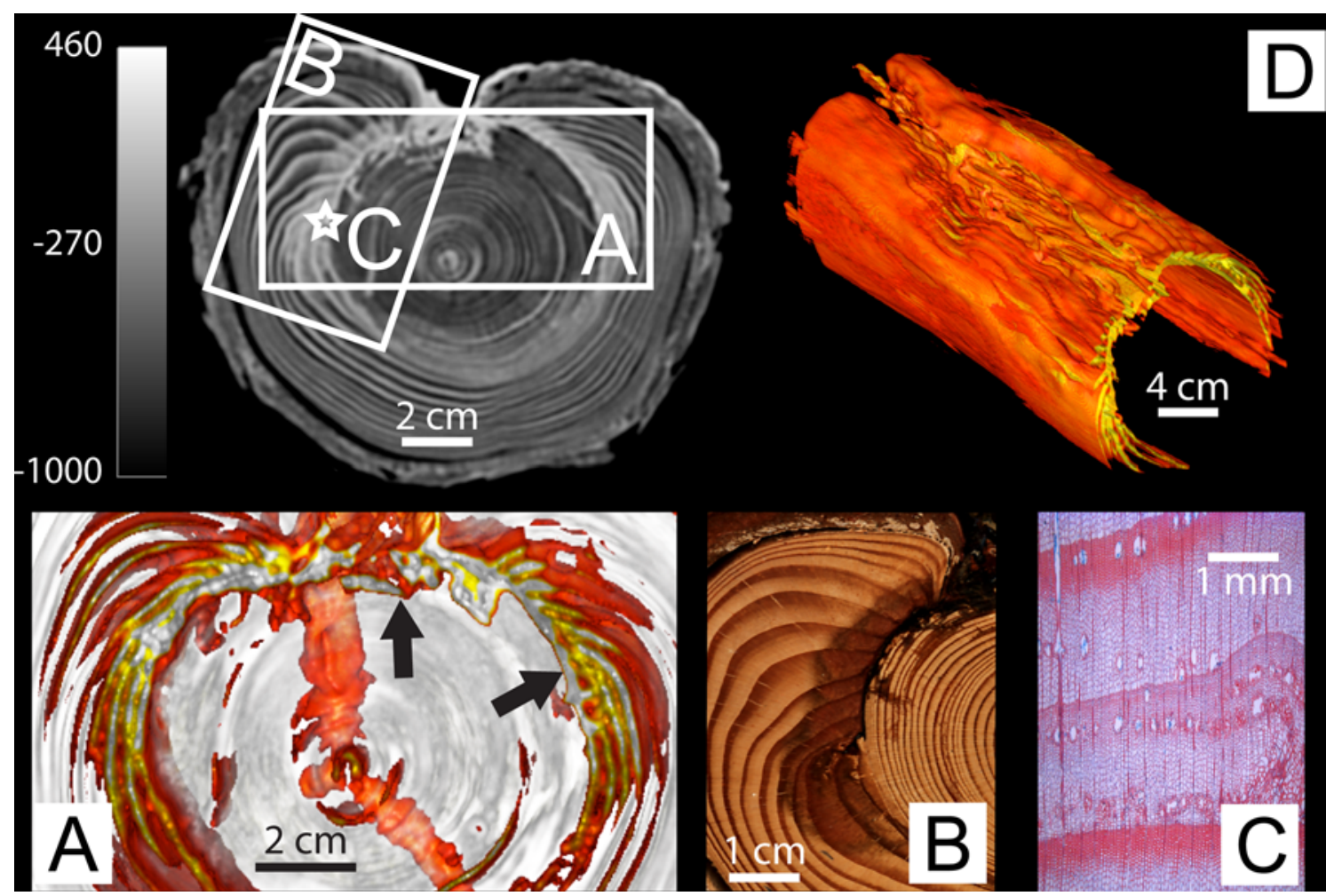

Fig. 2 Images of a European larch (L. decidua Mill.) stem with a scar affecting roughly $50 \%$ of its circumference (inset lower right): a detailed view of wound effects with highest densities in white and bright yellow, and lower densities in red (i.e. compression wood or chaotic tissue structures in the callus pad). The line indicated with black arrows points to the presence of barrier zones (compartmentalization).
The clear red and pink structures are (hidden) branches, $\mathbf{b}$ details of the callus pad formed after wounding and pre-wounding rings have been removed. Note the differences in closure rate and increment laid down on either side of the wound, $\mathbf{c}$ macroscopic view of the callus pad and the abundance of resin (dark brown structures), $\mathbf{d}$ micro-section of the callus tissue and resin ducts overgrowing pad and associated callus tissue formation with denser cells only became a priority during latewood formation.

The zones appearing in yellow and light orange represent surfaces with high densities and designate zones with a concentration of resin and tangentially aligned series of ducts (TRD). The formation of TRD has been described extensively in the literature and represents a tree's reaction to protect itself from decay and pathogens (e.g., Bannan 1936; Shigo 1984; Smith 2006). Interestingly, TRD continue to be formed next to the wound several years after the impact, an observation, which is consistent with previous wood-anatomical investigations on trees affected by mechanical disturbance under natural conditions (e.g., Stoffel and Hitz 2008; Schneuwly et al. 2009a, b). Noteworthy, the tangential extent of TRD is more pronounced left of the wound and thus points to larger cambial damage in this segment of the stem.

Another interesting feature is the reddish-yellow line highlighted with an arrow in Fig. 2a. This feature represents a small portion of the walls which trees form following wounding to compartmentalize and to protect the newly formed rings from decay. The limited resolution of medical XRCT prevents a complete illustration of these walls, but provides prime insights into a wound-related feature, which cannot easily be seen using conventional 2D assessments of wounds with cross-sections.

Figure $2 \mathrm{~d}$ represents a 3D cut out of the unprocessed data where growth rings formed prior to wounding have been removed. Besides illustrating zones of callus tissue and TRD, this cut also exhibits spatial differences in wound closure and pad thickness and points to the privileged closure of the injury from its upper and lower ends. XRCT imagery can thus also be used for a spatially explicit quantification of wound closure rates as recently tested by Schneuwly-Bollschweiler and Schneuwly (2012) for 2D samples (cross-sections) of $L$. decidua, P. abies and A. alba.

Figures 3 presents XRCT raw data and density anomalies of a Picea abies tree wounded by rockfall under natural condition. Similar to the anomalies presented for the $L$. decidua sample (Fig. 2a), we observe an abundance of resin and the presence of TRD, characterized by the yellowish surfaces in the image, as well as chaotic callus 


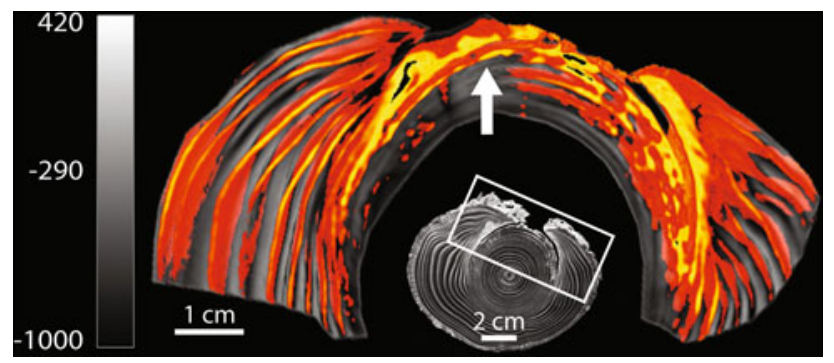

Fig. 3 Norway spruce [P. abies (L.) Karst.] tree with mechanical damage caused under natural condition (inset). Resin and associated tangential rows of traumatic resin ducts (yellowish segments) are abundant around the wound and chaotic callus tissue structures predominate in the callus pad overgrowing the wound. Noteworthy, resin penetrates into pre-wounding growth rings, also in unclosed areas of the wound (see arrow) subject to aeration and dessiccation

tissue structures in the callus pad overgrowing the wound. While more abundant at the time of wounding and even penetrating into pre-wounding growth rings, resin production is less widespread in the $P$. abies sample as compared to $L$. decidua in the present case. The more localized presence of TRD in $P$. abies clearly reflects the smaller scar size and presumably smaller impact energies and results do not therefore contradict findings of Schneuwly et al. (2009a) who reported TRD to be more abundant in $P$. abies than in L. decidua.

The cross-section illustrated in Fig. 4 is from an A. alba tree impacted by rockfall under natural conditions. In contrast to the other samples shown in this study it does not exhibit areas with increased presence of resin or TRD, but several zones with impact-related compression wood. These zones of compression wood formation are apparent from the XRCT image (Fig. 4, inset) and represented in greater detail in Fig. 4a, b. Noteworthy, in contrast to the callus tissue zones illustrated for L. decidua or P. abies, the density of tracheid cells is not only increased in latewood, but also present in earlywood cells. The earlywood portion of the increment ring nevertheless shows significantly lower densities (reddish-orange tones) as compared to the much denser latewood layers represented in yellow and white. The predominance of compression wood (also see Fig. $4 a^{\prime}$ for a detailed macroscopic view of the reaction wood) and the associated scarcity of TRD in A. alba

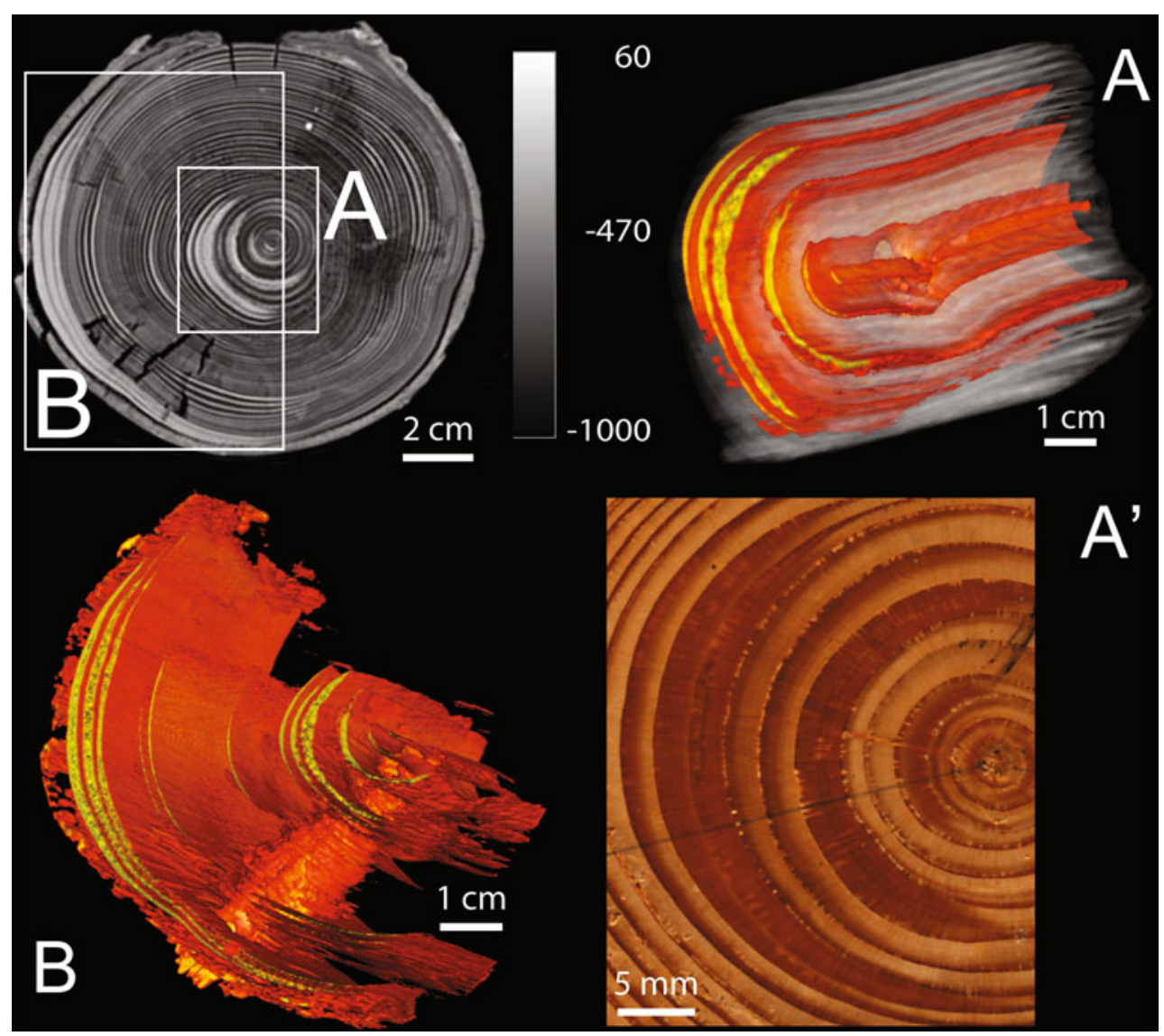

Fig. 4 Cross-section of a Silver fir (A. alba Mill.) tree (inset). In contrast to the other species, $A$. alba does not produce abundant resin (ducts), but several zones with impact-related compression wood: a detailed view of areas with compression wood close to the pith
[XRCT and $\left(\mathbf{a}^{\prime}\right)$ macroscopic views] and $\mathbf{b}$ compression in the outermost rings as a reaction of the stem to mechanical impact and subsequent destabilization of its trunk. Note the differences in wood density due to the presence of a branch 
confirm previous findings of Bannan (1936), Stoffel et al. (2005) and Schneuwly et al. (2009a).

\section{Conclusion}

The main purpose of using medical XRCT is the ability to visualize wood samples in full $3 \mathrm{D}$ and to extract zones of anomalous density. Zones or entire increment rings with higher or lower densities mainly indicate smaller cells with thicker cell walls (e.g., compression wood) or resin-saturated areas representing trees' reactions to mechanical damage. A visualization of damage and related growth anomalies in 3D enhances our understanding of growth reactions in trees to mechanical disturbance and allows more comprehensive analysis and documentation of processes of wound healing and compartmentalization, especially if combined with results from conventional 2D wood-anatomical and/or phytochemical analyses.

Acknowledgments The authors acknowledge access to the XRCT provided by the Forensic Institute, University of Bern and would like to thank Prof. M. Thali for permissions. Scanning was performed by Mohan Somasundaram.

\section{References}

Bannan MW (1936) Vertical resin ducts in the secondary wood of the Abietineae. New Phytol 35:11-46

Bill J, Daly A, Johnsen O, Dalen KS (2012) DendroCT-dendrochronology without damage. Dendrochronologia 30:223-230

Bollschweiler M, Stoffel M, Schneuwly DM, Bourqui K (2008) Traumatic resin ducts in Larix decidua stems impacted by debris flows. Tree Physiol 28:255-263

Brazee NJ, Marr RE, Gocke L, Van Wassenaer P (2010) Nondestructive assessment of internal decay in three hardwood species of northeastern North America using sonic and electrical impedance tomography. Forestry 84:33-39

Cormack AM (1963) Representation of a function by its line integrals, with some radiological applications. J Appl Phys 34:2722-2727

Cruickshank MG, Lejour D, Morrison DJ (2006) Traumatic resin canals as markers of infection events in Douglas-fir roots infected with Armillaria root disease. For Pathol 36:372-384

Delvaux C, Sinsin B, Van Damme P, Beeckman H (2010) Wound reaction after bark harvesting: microscopic and macroscopic phenomena in ten medical tree species (Benin). Trees 24:941-951

Duliu OG (1999) Computer axial tomography in geosciences: an overview. Earth Sc Rev 48:265-281

Eyles A, Davies NW, Mohammed C (2003) Wound wood formation in Eucalyptus globules and Eucalyptus nitens: anatomy and chemistry. Can J Forest Res 33:2331-2339

Hartig T (1844) Ambrosia des Bostrichus dispar. Allg Forst- Jagdztg 13:73-74

Larsson B, Bengtsson B, Gustafsson M (2004) Nondestructive detection of decay in living trees. Tree Physiol 24:853-858

Lawday G, Hodges PA (2000) The analytical use of stress waves for the detection of decay in standing trees. Forestry 73:447-456
Lev-Yadun S (2002) The distance to which wound effects influence the structure of secondary xylem of decapitated Pinus pinea. J Plant Growth Regul 21:191-196

Lindgren O, Davis J, Wells P, Shadbolt P (1992) Non-destructive wood density distribution measurements using computed tomography. Eur J Wood Prod 50:295-299

Müller U, Bammer R, Halmschlager E, Stollberger R, Wimmer R (2001) Detection of fungal wood decay using magnetic resonance imaging. Holz Roh- Werkstoff 59:190-194

Nagy NE, Franceschi VR, Solheim H, Krekling T, Christiansen E (2000) Wound-induced traumatic resin duct development in stems of Norway spruce (Pinaceae): anatomy and cytochemical traits. Am J Bot 87:301-313

Oldendorf WH (1961) Isolated flying-spots detection of radiodensities discontinuities displaying the internal structural pattern of a complex object. IRE Trans Bio Electron BME 8:68-72

Ostrofsky WD, Shortle WC (1989) Application of the shigometer for assessing tree and forest health and wood product quality. Rev Tropic Plant Pathol 6:39-57

Oven P, Merela M, Mikac U, Sersa I (2008) 3D magnetic resonance microscopy of a wounded beech branch. Holzforschung 62:322-328

Rademacher P, Bauch J, Shigo AL (1984) Characteristics of xylem formed after wounding in Acer, Betula, and Fagus. IAWA Bull 5:141-150

Rajput KS, Sanghvi GV, Koyani RD, Rao KS (2009) Anatomical changes in the stems of Azadirachta indica (Meliaceae) infected by pathogenic fungi. IAWA J 30:27-36

Rier JP, Shigo AL (1972) Some changes in red maple, Acer rubrum tissues within 34 days after wounding in July. Can J Bot 50:1783-1784

Romero C, Bolker BM, Edwards CE (2009) Stem responses to damage: the evolutionary ecology of Quercus species in contrasting fire regimes. New Phytol 182:261-271

Rosset A, Spadola L, Ratib O (2004) OsiriX: an open-source software for navigating in multidimensional DICOM images. J Digit Imaging 17:205-216

Ruel JJ, Ayres MP, Lorio PL (1998) Loblolly pine responds to mechanical wounding with increased resin flow. Can J For Res 28:596-602

Sarigul E, Abbott AL, Schmoldt DL (2003) Rule-driven defects detection in CT images of hardwood logs. Comput Electron Agric 41:101-119

Schneuwly DM, Stoffel M (2008) Changes in spatio-temporal patterns of rockfall activity on a forested slope-a case study using dendrogeomorphology. Geomorphology 102:522-531

Schneuwly DM, Stoffel M, Dorren LKA, Berger F (2009a) Threedimensional analysis of the anatomical growth response of European conifers to mechanical disturbance. Tree Physiol 29:1247-1257

Schneuwly DM, Stoffel M, Bollschweiler M (2009b) Formation and spread of callus tissue and tangential rows of resin ducts in Larix decidua and Picea abies following rockfall impacts. Tree Physiol 29:281-289

Schneuwly-Bollschweiler M, Schneuwly D (2012) How fast do European conifers overgrow wounds inflicted by rockfall? Tree Physiol. doi:10.1093/treephys/tps059

Seifert T, Nickel M, Pretzsch H (2010) Analysing the long-term effects of artificial pruning of wild cherry by computer tomography. Trees 24:797-808

Shigo AL (1984) Compartmentalization: a conceptual framework for understanding how trees grow and defend themselves. Ann Rev Phytopathol 22:189-214

Shortle WC, Dudzik KR, Smith KT (2010) Development of wood decay in wound-initiated discolored wood of eastern red cedar. Holzforschung 64:529-536 
Smith KT (2006) Compartmentalization today. Arboric J 29:173-184

Socco LV, Sambuelli L, Martinis R, Comino E, Nicolotti G (2004) Feasibility of ultrasonic tomography for nondestructive testing of decay in living trees. Res Nondestruct Eval 15:31-54

Stobbe H, Schmitt U, Eckstein D, Dujesiefken D (2002) Developmental stages and fine structure of surface callus formed after debarking of living lime trees (Tilia sp.). Ann Bot 89:773-782

Stoffel M, Bollschweiler M (2008) Tree-ring analysis in natural hazards research-an overview. Nat Hazard Earth Syst Sci 8:187-202

Stoffel M, Hitz OM (2008) Rockfall and snow avalanche impacts leave different anatomical signatures in tree rings of juvenile Larix decidua. Tree Physiol 28:1713-1720
Stoffel M, Schneuwly D, Bollschweiler M, Lièvre I, Delaloye R, Myint M, Monbaron M (2005) Analyzing rockfall activity (1600-2002) in a protection forest-a case study using dendrogeomorphology. Geomorphology 68:224-241

Stoffel M, Bollschweiler M, Butler DR, Luckman BH (2010) Tree rings and natural hazards: a state-of-the-art. Springer, Berlin, Heidelberg, New York 505

Wei Q, Chui YH, Leblon B, Zhang SY (2009) Identification of selected internal wood characteristics in computed tomography images of black spruce: a comparison study. J Wood Sci $55: 175-180$

Wilkes TE, Stock SR, De Carlo F, Xiao X, Faber KT (2009) X-ray micro-computed tomography of beech wood and biomorphic $\mathrm{C}$, $\mathrm{SiC}$ and $\mathrm{Al} / \mathrm{SiC}$ composites. Phil Mag 89:1373-1389 